\title{
Implementing a Graphic Organizer Active Learning Exercise with an Interactive Lesson Template
}

Adam C. Welch, PharmD; Michele H. Williams, PhD

East Tennessee State University

\begin{abstract}
Objective: To describe a systematic approach to active learning using a lesson template with a graphic organizer activity.

Innovation: The authors describe a tool that can be used to incorporate a graphic organizer activity into a traditional lecture class to promote active learning. This interactive template offers a step-by-step process to plan and implement a graphic organizer activity. The graphic organizer was used in a contact dermatitis lecture as part of a Nonprescription Medicines course for first year pharmacy students.

Critical Analysis: A survey of students immediately after the activity identified that students agreed they were interested in the activity, were engaged with the activity, and perceived an understanding of the course material. An instructor reflection revealed that students were excited and identified some instructor challenges to executing the activity.

Next Steps: Instructors interested in using graphic organizers in lectures can refer to this approach for guidance. In addition to a graphic organizer, the structure of this template can be applied to different active learning activities, thus creating consistency in delivering active learning.
\end{abstract}

Keywords: Active learning, graphic representation, reflective practice, concept maps, pharmacy education

\section{Description of the Problem}

Accreditation Council for Pharmacy Education (ACPE) Standards, 2016 call for instructional methods that actively engage learners and stimulate higher order thinking, problem solving, and clinical reasoning skills. ${ }^{1}$ Guidance in the Standards on how to implement these active learning strategies in the classroom is lacking. Pharmacy instructors wishing to incorporate active learning in their instruction may encounter a time-consuming search to find techniques to match their content and achieve the appropriate level of learning in Bloom's cognitive and affective domains to suit their needs. This situation presents a challenge to new faculty who are more likely to embrace active learning strategies, but may not have time to amass an assortment of techniques. ${ }^{2}$

According to Stewart and colleagues, a majority of pharmacy faculty report the use of active learning techniques during instruction. ${ }^{3}$ Graphic organizers are a broad category of active learning that describes two-dimensional visual representations of knowledge, including pictures, infographics, concept maps, flow charts, and tables. Vadlapatla and colleagues found that students who used concept mapping reported improved understanding of concepts in a pharmaceutics course. ${ }^{4}$ The use of graphic novels or comic books has been used as a pedagogical tool to help students remember concepts. ${ }^{5}$

Corresponding author: Adam C. Welch, PharmD

Bill Gatton College of Pharmacy

East Tennessee State University

Johnson City, TN 37614

Email: welcha1@etsu.edu

Phone: 423-439-6334
Teaching students to use graphic organizers in the classroom has implications outside of the classroom, as well. Carr-Lopez and colleagues found that not only do graphic organizers in the form of concept maps facilitate meaningful learning in the pharmacy classroom, but once students learn to use them, they utilize them beyond the classroom to study for additional courses. ${ }^{6}$ Furthermore, encouraging students to draw to-belearned material enhances their ability to remember more than do mnemonic devices. ${ }^{7}$

In 1999, Macpherson wrote a booklet, later published on the Creative Commons in 2015 that offered a print template for instructors to use to incorporate what was then called collaborative learning structures into their classes. ${ }^{8}$ While the article provides a useful tool, it does not provide a digital option and it is better suited to undergraduate classrooms. This report describes an updated and more interactive digital version of a planning template that is geared toward pharmacy school instruction.

\section{Statement of the Innovation}

The authors developed an interactive PDF document containing step-by-step guidance for planning and implementing a graphic organizer exercise employing small groups of students.

\section{Description of the Innovation}

While requirements for preparing active learning strategies can vary, these techniques work best when they are well planned. A variety of exercises to promote active learning increases the likelihood that the activity will match well with the content and the learning objectives. ${ }^{2,9}$ Using a thoughtful approach in the planning and delivery of instruction in the classroom helps to provide a more consistent and meaningful learning experience for students. A graphic organizer activity helps students break down concepts and examine relationships. Additionally, 
drawing concepts to-be-learned initiates dual coding (pairing pictures with verbal labels) and elaborative thinking (elaborating on the meaning of words and concepts) both of which facilitate remembering.

A Develop a Graphic active learning template was created after numerous conversations between the academic specialist and instructors who generally wished to integrate more active learning methods into their classes. This template was used in a Non-Prescription Medicines course (Over-the-Counter or OTC course). The OTC course, offered spring semester during the first professional (P1) year, meets once weekly for two hours and has been taught by the same instructors for several years. One instructor chose the Develop a Graphic template to use with the lesson on mild, moderate, and severe allergic contact dermatitis. Prior to using this template, the instructor's typical lecturing techniques included PowerPoint slides with interspersed images, brief videos, and cases illustrating key concepts.

After the instructor selected Develop a Graphic, the template was used to plan the lesson. See Figure 1 for an executed example of the template. The instructor collaborated with the college's academic specialist to move through each section on the template to plan all aspects of the class session including practical factors such as class size, time needed to complete the activity and materials needed. The template was revised through this process to remove jargon and clarify instructions and guidance.

The activity included students working in groups to differentiate treatment options for mild, moderate, and severe allergic contact dermatitis. The first hour of the class included a contact dermatitis lecture during which the instructor provided a brief example of a graphic organizer by drawing a tortoise and hare on the whiteboard to illustrate the differences between allergic and irritant contact dermatitis. The instructor emphasized that the process of drawing a visual representation of course material was the important part of the learning process, and not the ability to draw or be artistic. See Figure 2 for a re-creation of the instructor's graphic.

For the activity, the students formed small groups of four to five and spent the final 30 minutes of the contact dermatitis lecture creating a graphic representation using large sheets of paper and colored markers. Groups were tasked with creating an illustration that described treatment options for mild, moderate, and severe allergic contact dermatitis. The instructor and the academic specialist circulated throughout the classroom during this time answering questions, offering guidance, and encouraging collaboration.

When the drawings were complete, students presented their group graphics to the class with informal three-minute presentations. Examples included drawings of hot sauce (mild, spicy, and extra spicy) to indicate increasing levels of severity of allergic contact dermatitis. Another drawing depicted a traffic light (green, yellow, and red). One drawing illustrated babies with increasingly advanced motor skills to represent increasing severity with a crawling baby representing mild dermatitis, a walking baby for moderate dermatitis, and a skateboarding baby to depict severe dermatitis. After the class ended, each group's graphic was digitally captured and made available to the entire class as a study aid on the course online learning management system, Desire2Learn. This study received exempt approval from the University's IRB.

\section{Critical Analysis}

Students were engaged in the small group activity, talking and laughing while brainstorming ideas. The palpable shift in energy from passivity to lively interaction was encouraging. At the end of the class, students were given a 10-question Likerttype paper survey to determine their level of engagement with, and interest in the activity, and their perceived understanding of the material. The survey utilized a six-point scale ranging from 1- strongly disagree to 6 - strongly agree, with no neutral option. The median response for each of the ten survey questions was 5 (agree). Overall, student perception of the graphic organizer activity appeared to be positive. A paired samples t-test revealed that students rated the mean (SD) of the engagement questions (5.15 [0.57]) more positively than understanding (4.97 [0.81]), $\mathrm{t}=-2.33, \mathrm{p}=0.024$.

In addition to the student survey, the instructor was asked to reflect on the experience by answering a brief series of openended questions. A summary of the reflection showed that the instructor chose a graphic organizer because of anecdotally hearing that students think of themselves as "visual learners." The instructor felt the most challenging part of the activity was formulating the question for students to create the graphic organizer. Instructor reflection suggested that some groups stopped at distinguishing between the levels of disease without going into treatment. While the activity appeared to create excitement, the instructor felt that $\mathbf{3 0}$ minutes was not enough time, recommending 40 minutes instead.

\section{Key Issues}

Observation of students' classroom behavior indicated that students clearly enjoyed the activity. Students perceived engagement in the activity more positively than understanding of the material. It is possible the difference was attributable to the survey being administered at the end of the contact dermatitis lecture before the graphics were made available as a study tool online. Understanding of the course content related to the activity could be more directly assessed through exam questions. This study did not link the objective of the graphic organizer to an item on an exam. While determining the graphic organizer objective was a challenging to the instructor, aligning course and lecture objectives with the active learning could provide some guidance. 


\section{Next Steps}

This note specifically addresses the creation of a graphic organizer, but this type of step-wise template can be applied to many different active learning structures. Moving forward, the authors are creating additional activity templates to guide faculty in adopting active learning strategies. Some of these activities are well known, such as think-pair-share or fishbowl, and others are less well known in pharmacy education, such as creating a wanted poster. Instructors interested in using graphic organizers as an active learning tool in a lecture can refer to the template in Figure 1 as a guide. A blank copy of the interactive PDF is available upon request.

Acknowledgements: None Conflicts of Interest: None Funding: None

\section{References}

1. Accreditation Council for Pharmacy Education. Accreditation Standards and Key Elements for the Professional Program in Pharmacy Leading to the Doctor of Pharmacy Degree ("Standards 2016"). Published February 2015. Available at: https://www.acpeaccredit.org/pdf/Standards2016FINAL.pdf. Accessed April 12, 2019.

2. DeWitt R. Planning for Active Learning in the Didactic Classroom. J Physician Assist Educ. 2019;30(1):41-46. doi:10.1097/JPA.0000000000000236

3. Stewart DW, Brown SD, Clavier CW, Wyatt J. ActiveLearning Processes Used in US Pharmacy Education.

Am J Pharm Educ. 2011;75(4):68. doi:10.5688/ajpe75468

4. Vadlapatla R, Kaur S, Zhao Y. Evaluation of student perceptions of concept mapping activity in a didactic pharmaceutics course. Curr Pharm Teach Learn. 2014;6(4):543-549. doi:10.1016/j.cptl.2014.04.014

5. Muzumdar J. An Overview of Comic Books as an Educational Tool and Implications for Pharmacy. Innov Pharm. 2016;7(4). doi:10.24926/iip.v7i4.463

6. Carr-Lopez SM, Galal SM, Vyas D, Patel RA, Gnesa EH. The Utility of Concept Maps to Facilitate Higher-Level Learning in a Large Classroom Setting. Am J Pharm Educ. 2014;78(9):170. doi:10.5688/ajpe789170

7. Fernandes MA, Wammes JD, Meade ME. The Surprisingly Powerful Influence of Drawing on Memory. Curr Dir Psychol Sci. 2018;27(5):302-308. doi:10.1177/0963721418755385

8. Macpherson A. Cooperative Learning Group Activities for College Courses: A Guide for Instructors. Kwantlen University College; 2007. https://books.google.com/books?id=ifZdswEACAAJ.

9. Auster ER, Wylie KK. Creating Active Learning in the Classroom: A Systematic Approach. J Manag Educ. 2006;30(2):333-353. doi:10.1177/1052562905283346 
Figure 1. Executed template for Developing a Graphic.

The template outlines a stepwise approach for using a graphic organizer activity during a class lecture.

(a) BILL GATTON COLLEGE of PHARMACY EAST TENNESEE STATE UNIVERSTY

\section{Developing a Graphic}

How this works: Using a graphic organizer (see attached file) or drawing a visual representation of concepts helps students to examine relationships, break down concepts, and think critically by analyzing information and making inferences. Visual representations help with retention by pairing pictures with concepts.

Blooms Level: Analyze. Verbs: Classify, compare, distinguish, examine, list, divide, infer

Recommended uses: Cause and effect relationships, disease states, processes, systems and functions

Time needed: Approximately 40 minutes

Recommended Group Size : 2 to 5

Materials needed: Markers of various colors (at least 4 per group , large sheets of paper (one per group)

Objectives: (What will students be able to do/know by the end of the activity?) Students will be able to

Describe the treatment options for mild, moderate, and severe allergic dermatitis.

Introduction: Purpose of the activity. How it fits into the course. Give students the "why" of the activity. Tell students that their patients will ask for tretment options for contact dermatitits, and that understanding the severity of the condition will help determine which OTC product would be best to use. This activity will help you to distinguish between the severity of contact dermatitis in a memorable way to better treat patients with OTC medicines.

Your plan, step-by-step
1. Lecture with slides providing overview of
contact dermatitis and treatment.
2. Draw example of tortoise and hare to
describe allergic vs. contact dermatitis.
3. Give students 15 min. to draw treatment
options for mild, moderate, and severe
disease.
4. When complete, ask students to sign their
group's graphic and turn in.
5. Tell students pictures of their work will be
posted on D2L learning site.

Suggested Directions, step-by-step

1. Present an overview of the concepts

2. Tell students that they will be forming small groups and will have 5 minutes to plan and 15 minutes to develop a visual representation (show examples) of [concepts to draw]

3. Identify what a successful graphics will include

4. 10 minutes to present graphic to class or another group

5. Group members sign the graphic and turn in or take a picture and submit electronically

Recap and Check for Understanding:

circulate and answer questions as students draw. Ask groups to volunteer to present their graphics to the class.

Debrief Activity : Ask students to write their answer to the following question as an exit ticket. How did input from the group and the visual representation add to your understanding of [the concept]?

Exam Questions:

None added.

Notes for Next Year:

Allow more time for activity. Use the recommended 40 minutes instead of 30 minutes. 
Figure 2. Instructor's graphic representation of the differences

between irritant and allergic contact dermatitis using a tortoise and hare analogy.

$\mathrm{ACD}=$ Allergic contact dermatitis, $\mathrm{ICD}=$ Irritant contact dermatitis, $\mathrm{HRS}=$ hours

Note: Each symbol represented symptoms that were verbally discussed in the class while the drawing was made on the white board. For example, circles represented vesicles, the zig-zag shapes resembling a lightning bolt represented itching, and the triangles resembling exploding volcanoes represented pustules 